\title{
APLICAÇÃO DE CONCEITOS DA ECOLOGIA INDUSTRIAL NO DESIGN DE PRODUTOS EM ECO-COMPÓSITO DE RESÍDUOS PARTICULADOS E PEDAÇOS DESCARTADOS DE MADEIRA
}

\section{APPLICATION OF ECOLOGY INDUSTRIAL CONCEPTS IN PRODUCT DESIGN WITH WOOD PARTICULATE WASTE ECO-COMPOSITE AND DISCARDED WOODEN PIECES}

\author{
Marcelo Geraldo Teixeira ${ }^{1}$; Elio Carlos dos Santos Junior ${ }^{2}$; Evanes Copque dos Santos Couto ${ }^{3}$ \\ ${ }^{1}$ Faculdade Ruy Barbosa - FRB - Salvador/BA - Brasil \\ marcelomgt@gmail.com \\ ${ }^{2}$ Faculdade da Cidade - São Paulo/SP - Brasil \\ elio-paulista@hotmail.com \\ ${ }^{3}$ Faculdade da Cidade - Salvador/BA - Brasil \\ kopke_@hotmail.com
}

\begin{abstract}
Resumo
Este artigo tem como objetivo demonstrar a aplicação de conceitos da Ecologia Industrial e do Eco-design como fundamentos para o design de produtos construídos com resíduos particulados e pedaços sólidos descartados de madeira, considerados como lixo sem uma solução aparente. A pesquisa atual teve como ponto de partida estudos anteriores sobre produção de um compósito ecológico feito de serragem de madeira residual, a qual foi ampliada para aproveitar partes de madeira sólida descartada. Com base no conceito da circulação de recursos proposto pela Ecologia Industrial e por requisitos do Eco-design, foi projetado um modelo de demonstração, na forma de um tampo de mesa através do método em três fases: na Fase I realizou-se a coleta e classificação do resíduo de madeira em uma indústria madeireira; na Fase II, a concepção do produto e na Fase III, a produção do modelo de demonstração. A solução encontrada foi usar os distintos resíduos em partes diferentes do modelo, gerando assim um resultado plasticamente agradável.
\end{abstract}

Palavras-chave: Ecologia Industrial; Eco-Design, resíduo de madeira.

\section{Introdução}

A exploração excessiva dos recursos naturais, assim como a disposição de resíduos, ambos atribuídos às atividades antrópicas, tem sido apontadas como duas das grandes causas de problemas ecológicos contemporâneos. Assim, torna-se imperativo o emprego de alternativas tecnológicas ambientalmente sustentáveis, que possam minimizar o impacto ambiental tanto no momento da obtenção de insumos e nos processos de fabricação de produtos, quanto no momento do descarte de resíduos. 
As indústrias de base florestal, dentre elas a indústria madeireira, são um exemplo de um processo ineficiente, responsável, segundo Schirmer et al (2010), "pela geração de grandes quantidades de resíduos, cujo volume e natureza variam em função das características do processo produtivo empregado". Estas indústrias apresentam problemas desde a extração dos recursos naturais, passando pela fabricação dos produtos e finalizando tanto no descarte de resíduos industriais quanto nos produtos de madeira no final da sua vida útil. Isso significa um grande desperdício dos recursos madeireiros principalmente das florestas nativas, muitas delas em processo de extinção tal como a Mata Atlântica. A ampla utilização da madeira plantada e certificadas, como a do eucalipto, pode diminuir o consumo da madeira de espécies nativas, cada vez mais sujeitas às restrições de corte. Entretanto, o aproveitamento dos troncos das árvores como matéria prima pelas indústrias madeireiras está em torno de 30\% a 60\% (FREITAS, 2000). Esse quadro se agrava com o aumento da procura e consumo de madeira sem que se apresentem materiais alternativos para ela, levando a um quadro de carência mundial desta matéria prima (GOMES e SAMPAIO, 2004). Apesar de haver processos de aproveitamento destas sobras, como o exemplo da lenha, dos briquetes ou como "cama-de-galinha" nas granjas, muitas destas soluções agregam baixo valor ao resíduo (TEIXEIRA, 2005). Então, diante desse cenário, questiona-se sobre a possibilidade de concepção de novos produtos a partir deste tipo resíduo.

Este artigo tem como objetivo demonstrar o processo de concepção de produtos a partir de dois tipos de resíduos oriundos do processamento da madeira na fabricação de móveis domiciliares, exemplificado aqui como um tampo para mesa para ambientes recreativos. A pesquisa se fundamentou no conceito da Ecologia Industrial e em requisitos do Eco-Design, e usou como ponto de partida a pesquisa realizada por Teixeira (2005) na qual foi desenvolvido e testado um compósito com resíduo particulado de madeira. A pesquisa aqui relatada se justifica pela oportunidade de demonstrar o processo de aplicação deste compósito em um produto, ajudando a ampliar a literatura nesta área do conhecimento.

\section{Referencial teórico}

\subsection{Ecologia industrial e Eco-design}

A Ecologia Industrial é um conceito associado às Tecnologias Limpas, que tem como objetivos a prevenção da poluição pela redução da demanda de matérias primas e energia e a diminuição da devolução de resíduos e poluentes à natureza, integrando os processos artificiais aos meios naturais de forma sustentável (ISENMANN, 2003). Para isso, se propõe a utilização de matérias primas e energia em ciclos fechados, envolvendo os sistemas de produção e consumo de modo análogo aos processos naturais, possibilitando ao meio natural o processamento limpo de possíveis resíduos se estes existirem. O modelo ideal de referência seriam os sistemas naturais, 
fechados, nos quais não cabem os conceitos de resíduos e matéria prima. Não sendo possível repetilos, procurar-se-ia aproximar-se deles o mais possível. (KIPERSTOK e MARINHO, 2001)

Segundo Tanimoto (2004) a relação entre produtores e consumidores de materiais é análoga ao conceito de simbiose na qual, na natureza, seres de espécies diferentes convivem de forma que a soma de esforços coletivos supera a soma dos esforços individuais, promovendo uma interação social benéfica entre os participantes e destes, com a natureza. Desta maneira, segundo a Ecologia Industrial, o que é considerado resíduo em um processo produtivo é aproveitado como insumo em outro processo, formando, assim, um circuito fechado de aproveitamento e reciclagem de insumos e permitindo que a quantidade de material que transita na biosfera se mantenha constante. Isso resulta na redução tanto da demanda por recursos naturais, quanto na redução de resíduos minimizando, assim, a pressão sobre a natureza. Desta forma, um material deixa de ser resíduo pela sua valorização como matéria prima a ser usada na obtenção de novos produtos, usando de maneira quase completa todo recurso disponível. A figura 2 representa esse conceito.

Figura 2 - Descrição imagética do conceito dos ciclos fechados na Ecologia Industrial

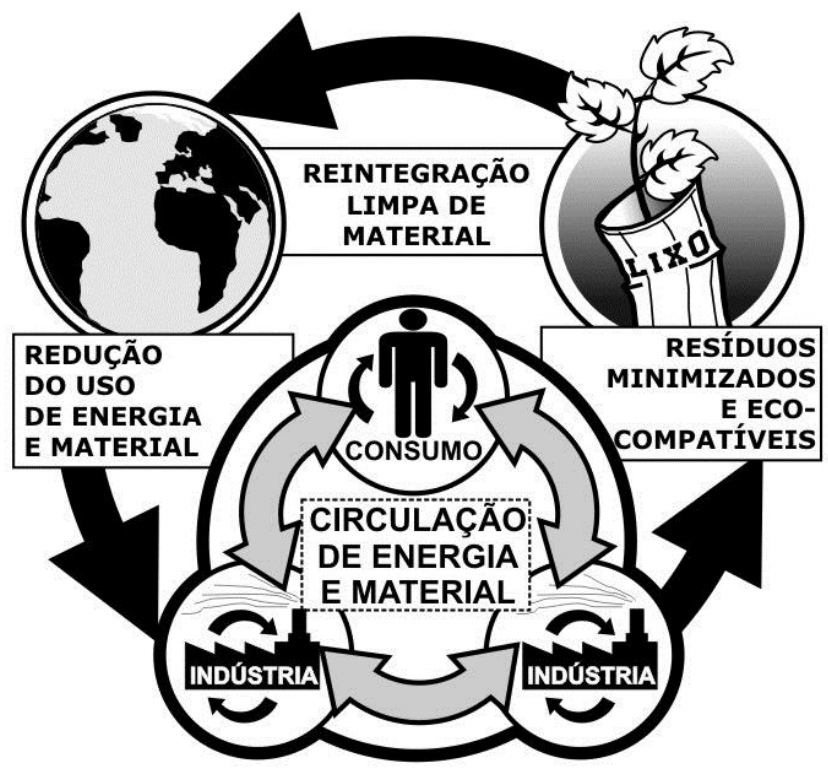

Fonte: Teixeira e Santos (2015)

O conceito de reciclagem normalmente está associado às alternativas fim de tubo, atuando depois do descarte de resíduos industriais ou de pós-consumo, na tentativa de trazer esses materiais aos processos produtivos. Tais alternativas, no entanto, não são tão eficientes quanto necessário, o simples fato de agir depois da geração de resíduos implica em soluções pouco eficientes de remediação. O aumento do consumo pode implicar no aumento de resíduo, pressionando as tecnologias Fim-de-Tubo aos seus limites de operação (TEIXEIRA, 2005).

Dentro da Ecologia Industrial, o conceito de reciclagem passa a ter, então, outra compreensão, abandonando a antiga idéia de ser uma opção fim-de-tubo, passando a operar 
resíduos industriais ou de pós-consumo em processos no quais não há o conceito de resíduo ou lixo, por adotar a idéia dos resíduos como insumos em circulação. Os exemplos do eco-parque da cidade dinamarquesa de Kalundborg, citado por Ehrenfeld e Gertler (1997) e Jacobsen (2006) ou do complexo ecológico papel/açúcar no estado indiano de Tamil Nadu, citado por Ramaswamy (2004) ou ainda as pesquisas nacionais realizadas por Alves e Trevisan (2014) e por Rodrigues, Peixoto e Xavier (2013), demonstram a viabilidade prática da Ecologia Industrial.

Para fazer com que produtos, materiais e energia circulem em ciclos fechados é necessário uma estratégia, ou um meio de inovação criativa (SILVA, 2004) de projetá-los, para que se encaixem na proposta da Ecologia Industrial. Allenby e Richards (1994) identificaram o Eco-design (DfE - Design for Environment) como uma das ferramentas para a realização desta proposta, estabelecendo a ideia de que a concepção de produtos seja ambientalmente correta. Fiksel (2009, p.83) o define como uma sistematização do design com requisitos que vão além da sua aplicação em prol do meio ambiente, envolvendo também a saúde e a segurança humana de forma sustentável, cujos requisitos devem ser aplicados em todas as fases e etapas do ciclo de vida de um produto. Manzini e Vezzoli (2002) estabeleceram tais requisitos, mostrados no Quadro 1.

Quadro 1 - Requisitos ambientais para o design de produtos sustentáveis

\begin{tabular}{|c|l|}
\hline Projetar para & \multicolumn{1}{c|}{ Conceito } \\
\hline Minimização dos recursos & $\begin{array}{l}\text { Redução do consumo de matéria e energia associado ao produto ou } \\
\text { serviço ao longo de todo seu ciclo de vida; }\end{array}$ \\
\hline $\begin{array}{c}\text { Escolha de recursos e processos de } \\
\text { baixo impacto ambiental }\end{array}$ & $\begin{array}{l}\text { Diminuição dos impactos ambientais pela escolha dos melhores recursos } \\
\text { materiais e energéticos; }\end{array}$ \\
\hline Otimização da vida útil dos produtos & $\begin{array}{l}\text { Evitar a degradação física, a obsolescência programada e a } \\
\text { obsolescência cultural e estética de produtos e serviços; }\end{array}$ \\
\hline Extensão da vida dos materiais & $\begin{array}{l}\text { Diminuição de resíduos e possibilidade do uso de materiais não-virgens } \\
\text { nas mais variadas possibilidades e durante o maior tempo possível; }\end{array}$ \\
\hline Facilitar a desmontagem & $\begin{array}{l}\text { Tornar ágil e econômico o desmembramento das partes componentes e a } \\
\text { separação dos materiais de fabricação dos produtos. Facilitar a } \\
\text { manutenção e atualização dos produtos; }\end{array}$ \\
\hline
\end{tabular}

Fonte: construído a partir de Manzini e Vezzoli (2002)

Segundo Manzini e Vezzoli (2002), quanto mais perto das etapas iniciais do projeto for o uso dos requisitos ambientais, maior será a eco-eficiência do produto desenvolvido. Observa-se a existência da preocupação com o ciclo de vida das matérias primas, sugerindo que tenham origem e destinos sustentáveis, sem quebrar o ciclo, ou seja, que possam ser recicladas e recicláveis. Segundo Teixeira (2005) essas metas podem ser desdobradas para que um produto seja eco-eficiente $\mathrm{O}$ Quadro 2 mostra alguns desses desdobramentos.

Quadro 2-Desdobramentos conceituais do quadro 1

\begin{tabular}{l|l} 
Projetar para & Conceito
\end{tabular}




\begin{tabular}{|c|c|}
\hline $\begin{array}{l}\text { Redução do uso de } \\
\text { recursos naturais }\end{array}$ & $\begin{array}{l}\text { - Conceber soluções com formatos e dimensões simplificadas; } \\
\text { - Conceber produtos mais leves, usando o mínimo de matéria prima. } \\
\text { - Usar materiais vindos de fontes abundantes; } \\
\text { - Usar materiais abundantes e sem restrição de uso; }\end{array}$ \\
\hline Redução de resíduos & $\begin{array}{l}\text { - Usar materiais reciclados e recicláveis; } \\
\text { - Usar materiais compatíveis entre si; } \\
\text { - Usar materiais que provenham de refugos de processos produtivos }\end{array}$ \\
\hline $\begin{array}{c}\text { Facilitar montagem e } \\
\text { desmontagem }\end{array}$ & $\begin{array}{l}\text { - Possibilitar o uso de peças em outros produtos; } \\
\text { - Escolher soluções técnicas que facilitem a montagem e/ou desmontagem dos } \\
\text { produtos }\end{array}$ \\
\hline $\begin{array}{l}\text { Tecnologias limpas e } \\
\text { processos sustentáveis }\end{array}$ & $\begin{array}{l}\text { - Selecionar tecnologias e processos de produção mais limpas e sustentáveis } \\
\text { disponíveis } \\
\text { - Selecionar processos mais acessíveis e de custo mais baixo possível }\end{array}$ \\
\hline
\end{tabular}

Fonte: construído a partir de Teixeira (2005)

O propósito de reunir vários requisitos, como vistos nos Quadros 01 e 02, é o de buscar requisitos compatíveis que tornem um produto proposto mais eco-eficiente, visto que o uso apenas de um destes requisitos não garante seu bom desempenho ambiental (TEIXEIRA, 2005).

\subsection{Resíduos do processamento de madeira}

Os resíduos sólidos de madeira são classificados como resíduos ligno-celulósicos, apresentando características variáveis devido a vários fatores tais como a diversidade de espécies de madeira usadas, as diversas granulometrias dos particulados ou as diversas condições de armazenamento, fatores que podem alterar suas características físicas. São de baixa densidade e não são tóxicos, se no seu volume não houver outros materiais, principalmente produtos químicos tais como conservantes, fungicidas, inseticidas, vernizes, tintas, dentre outros, que possam emitir gases ou vapores tóxicos durante processos de reciclagem ou de queima (QUIRINO, 2004). Livre destes materiais contaminantes, o resíduo pode ser considerado como banal e não inerte, pois é biodegradável, classificado pela NBR 10004 (ABNT, 1987) como Classe 2A, com possibilidades de ser reaproveitado por processos diferentes daqueles industriais iniciais e de ser transformado em produtos de uso similar ou diferente ao da madeira serrada inicial.

Segundo Teixeira (2005), os resíduos industriais de madeira são oriundos do processamento mecânico das toras de madeira sólida. Desde o corte e passando pelos procedimentos de desdobro, desengrosso, serragem e acabamento, dentre outros, há a geração de vários tipos de resíduos referentes a cada uma dessas etapas. De forma a sistematizar os processamentos da madeira sólida, Gonçalves e Ruffino (1989) estabelecem etapas produtivas junto com os resíduos gerados por cada etapa respectiva, como visto na Figura 1: 
Figura 1 - Processo de geração de resíduos de madeira

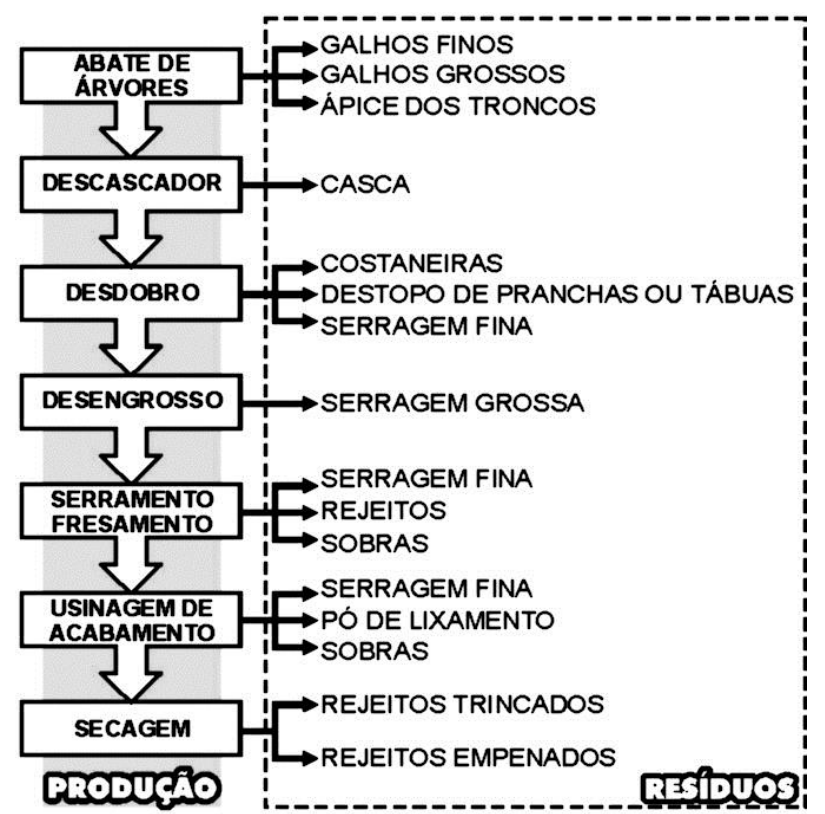

Fonte: Teixeira (2005), baseado em Gonçalves e Ruffino (1989)

Freitas (2000) afirma que somente $1 / 3$ à $2 / 3$ da madeira extraída é transformada em produtos finais. Os resíduos desta produção, portanto, somam-se como uma grande quantidade de madeira com poucas alternativas ambientalmente corretas. Para exemplificar essa quantidade, somente no estado do Pará, em 1998, foram gerados cerca de 7,025 milhões de metros cúbicos de resíduos de madeira (PINHEIRO, RENDEIRO e PINHO, 2004). Segundo Da Silva (2002), “tudo que não serve para o comércio regular vai para o lixo ou é queimado". Apesar dos esforços de vários pesquisadores, tais como Araújo (2003), Wiecheteck (2009) ou Silva (2011) em transformá-los em material energético, quando estes são queimados contribuem para o aumento da poluição do ar, lançando neste, segundo Oguntoke, Otusanya e Annegarn (2013), várias substâncias com potencial de impactar negativamente o meio ambiente, tais como o $\mathrm{NO}_{2}, \mathrm{SO}_{2}, \mathrm{CO}$ e $\mathrm{CO}_{2}$. A busca por melhores alternativas de aproveitamento de resíduos passa a ser, então, um dos principais objetivos em prol da sustentabilidade ambiental da indústria da madeira.

\subsection{Compósitos ecológicos}

Os compósitos são materiais desenvolvidos a partir da combinação de pelo menos dois tipos de materiais distintos: uma matriz, geralmente polimérica ou cimentícia; um reforço, na forma de fibras (BRASKEN, 2002) e, quando necessário, uma carga, um material particulado em pó. Estes, quando combinados no compósito, repassam a este parte das suas características ao mesmo tempo em que fazem surgir outras novas. Um dos compósitos mais populares é o Fiberglass, ou fibra de vidro, que usa como matriz resinas plásticas termofíxas, e fibras de vidro na forma de mantas e/ou tecidos. 
O eco-compósito surge quando seus componentes são oriundos de fontes renováveis, abundantes e não tóxicas, podendo ser reciclados e, alguns, biodegradáveis (TEIXEIRA, 2005). São exemplos de eco-compósitos aqueles que usam matrizes poliméricas e reforços de origem vegetal, tais como as resinas feitas com óleos da soja ou da mamona e as fibras de sisal ou curauá, respectivamente (TAKAHASHI et al, 2011). Entretanto, do ponto de vista da Ecologia Industrial, um compósito pode ser mais ambientalmente sustentável se seus componentes forem provenientes de resíduos, considerando, também, a possibilidade de serem produzidos e moldados por processos igualmente sustentáveis. Trata-se, portanto, de levar em conta a oportunidade de aproveitamento de uma classe de material de grande disponibilidade, mas que seria descartado como resíduo. O Quadro 3 mostra a variedade destes componentes, baseados na literatura estudada.

Quadro 3 - Alguns tipos de resíduos como componentes de compósitos de matriz termofixa

\begin{tabular}{|c|c|}
\hline COMPONENTE & DESCRIÇÃ̃O \\
\hline MATRIZES & $\begin{array}{ll}- & \text { Resinas termofíxas a partir de garrafas PET } \\
\text { - } & \text { Resinas baseadas em resíduos vegetais oleosos, como a casca } \\
\text { da castanha do caju. }\end{array}$ \\
\hline REFORÇOS & $\begin{array}{l}\text { - } \quad \text { Bagaço de cana e de outros vegetais } \\
\text { - } \quad \text { Cascas e palha de cereais: arroz, amendoim, etc. } \\
\text { - } \quad \text { Cascas de frutas, tais como o coco, abacaxi (coroa), etc. } \\
\text { - } \quad \text { Papel, papelão e demais resíduos celulósicos; } \\
\text { - } \quad \text { Sobras e resíduos de tecidos têxteis (jeans, brim, etc.) } \\
\text { - } \quad \text { Resíduos de lã animal }\end{array}$ \\
\hline CARGAS & $\begin{array}{ll}\text { - } & \text { Serragem de madeira sólida } \\
\text { - } & \text { Resíduos particulados de madeira reconstituída (MDF, etc.) } \\
\text { - } & \text { Sílica a partir de resíduos de vegetais como a cavalinha } \\
\text { - } & \text { Particulados cimentícios de obras da construção civil } \\
\text { - } & \text { Resíduos rochosos e cerâmicos particulados } \\
\text { - } & \text { Resíduos particulados de borracha de pneus } \\
\text { - } & \text { Cinzas e lamas industriais não tóxicas }\end{array}$ \\
\hline
\end{tabular}

Fonte: Construção própria baseada em Teixeira (2005), Silva (2012), Mazzetto, Lomonaco e Mele (2009), Alves et al (2007), Missagia (2013), Zonatti (2013), Silva (2012), Martuscelli (2013), Molinari (2007), Dos Santos (2007) e Souza (2008)

O uso de resíduos de madeira para a fabricação de produtos em compósitos, por exemplo, não é uma novidade, mas ainda pouco explorado, apesar das vantagens físicas, estéticas e ambientais que possui, além de estar disponível em grandes quantidades (TEIXEIRA, 2005). English et al (1996) referem-se às boas qualidades da farinha ou pó de resíduos de madeira e de papel, usados como carga em compósitos. Segundo esses autores, este resíduo em pó pode substituir as cargas inorgânicas e minerais, tais como talco ou carbonato de cálcio, na mesma função, com as vantagens ecológicas da redução de resíduos sólidos. As vantagens são: o baixo custo de aquisição de matéria prima, o preço acessível dos produtos gerados além das boas propriedades mecânicas do compósito.

Como exemplos do resíduo de madeira usados em eco-compósitos podem ser citadas as recentes pesquisas realizadas por El-Haggar e Kamel (2011), que apresentaram características 
básicas e discutiram vantagens e desvantagens da seleção de alguns dos seus componentes usados como matriz, reforço e cargas, e por Missagia et al (2013), que investigaram propriedades físicas e mecânicas de um eco-compósito de madeira particulada, cimento portland e silicato de magnésio com matriz epóxi.

\subsection{Quanto aos processos produtivos}

Cada matéria prima está associada ao seu respectivo processo produtivo. No caso dos compósitos de matriz termofixa, segundo Orth, Baldin e Zanotelli (2012), existem dois tipos principais de moldes usados, sendo os demais tipos, variantes desses primeiros: os moldes abertos: spray-up e hand lay-up, e os fechados: Resin Transfer Molding (RTM), Sheet Molding Compound (SMC) e Bulk Molding Compound (BMC), conforme mostrado na figura 3.

Figura 3 - Tipos básicos de molde para produtos em compósitos de matriz termofixa

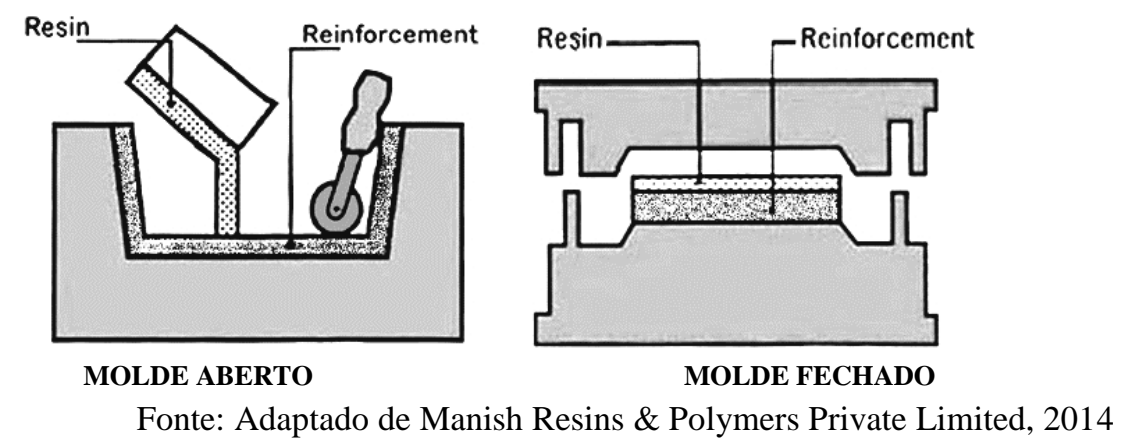

Nos processos manuais usam-se moldes abertos, onde é usada apenas uma das suas superfícies, na qual a peça será moldada e/ou laminada (BARANOWSKI \& SHREVE, 1981). Usam-se moldes simples, feitos geralmente de madeira ou fiberglass, e as resinas são endurecidas a frio, com o uso de catalisadores. São os processos mais simples e baratos, muito difundidos e usados na maioria das micro-indústrias de plásticos reforçados.

Já os processos com moldes fechados são caracterizados por terem duas partes do molde do tipo macho/fêmea, formando uma cavidade interna e oferecendo acabamento total à superfície do produto, sem expor assim, suas partes durante o processo de cura. Do ponto de vista da sustentabilidade ambos oferecem vantagens e desvantagens, conforme mostra a Quadro 4.

Quadro 4 - Principais conceitos de processos de produção de produtos em compósitos de matriz termofixa quanto à sustentabilidade ambiental

\begin{tabular}{|c|c|c|}
\hline Tipo do molde & Vantagem & Desvantagem \\
\hline ABERTO & $\begin{array}{l}\text { - Baixo custo, } \\
\text { - Baixo conhecimento para seu uso, } \\
\text { - Ferramental manual acessível, } \\
\text { - Baixo consumo de energia elétrica, } \\
\text { - Pode ser construído com materiais } \\
\text { diversos, como plástico reforçado, }\end{array}$ & $\begin{array}{l}\text { - Expõe o laminado aos elementos enquanto cura, } \\
\text { permitindo a emissão de substâncias químicas } \\
\text { voláteis, nocivas à saúde humana, } \\
\text { - Pouco controle da espessura do laminado, } \\
\text { permitindo gasto excessivo de material, } \\
\text { - Necessidade de rebarbação e de extenso }\end{array}$ \\
\hline
\end{tabular}




\begin{tabular}{|l|l|l|}
\hline & $\begin{array}{l}\text { madeira, gesso ou papel cartão, } \\
\text { - Tem menores restrições quanto às } \\
\text { dimensões e ao formato dos produtos } \\
\text { se comparado aos demais processos. }\end{array}$ & $\begin{array}{l}\text { lixamento das peças, resultando na geração de } \\
\text { resíduos sólidos difíceis de serem reciclados, } \\
\text { - Geração de material particulado por processos de } \\
\text { lixamento, nocivo à saúde humana. }\end{array}$ \\
\hline \multirow{6}{*}{ FECHADO } & - Emissão de vapores minimizada & - Custo e complexidade mais elevados, \\
& - Geração de resíduos sólidos & - Custo em ferramentas e máquinas de manufatura, \\
& minimizado pela diminuição da & - Uso de equipamentos com maior consumo de \\
& rebarbação e de processos de & energia elétrica, \\
& - Controle da espessura do laminado \\
& minimizando o gasto excessivo de \\
& material. & $\begin{array}{l}\text { Construção usando materiais específicos, como } \\
\text { plástico reforçado e metais; } \\
\text { - Menos acessível para micro e pequenas } \\
\text { produções; }\end{array}$ \\
& & Restrito a produtos de pequenas e médias \\
& dimensões.
\end{tabular}

Fonte: construção própria a partir de: Baranowski \& Shreve (1981); Clavadetscher (1981); Gay, Hoa e Tsai (2003); Teixeira (2005); Orth, Baldin e Zanotelli (2012)

Muitos dos processos derivados destes citados acima, se apresentam como soluções produtivas mais simples, baratas e acessíveis, tais como os processos RTM-L (Resin Transfer Molding - light), que usam moldes fechados leves, construídos geralmente de Fiberglass (Garay et al, 2011) ou o processo de Vacuum-Bag, que usa como parte do molde, um saco plástico fechado a vácuo. Segundo Vazzoler (2010) esses tipos de processos ratificam a vantagem de emitir baixas quantidades de substâncias químicas voláteis, além de não perderem a qualidade do que se está fabricando. A desvantagem desses processos está no custo de aquisição dos materiais e do ferramental exclusivos, acabando por afastar o interesse de pequenas empresas.

Compósitos baseados em madeira particulada e matriz termoplástica, conhecidos como Wood Plastic Composite (WPC), tem tido ampla comercialização em muitos países, principalmente na área da construção civil. Aplicações na forma de móveis para piscina, janelas e portas, são exemplos dessas possibilidades. Segundo Correa et al (2003) são inúmeras as vantagens em relação a produtos de madeira serrada, tais como maior resistência à umidade, à deterioração ambiental e a pragas; maior resistência ao empenamento e trincas, maior durabilidade, baixo custo de aquisição e manutenção, além de serem recicláveis.

Por outro lado, apesar de algumas pesquisas demonstrarem a possibilidade de uso de ecocompósitos baseados em matriz termofixa na fabricação de produtos, ainda há carência de experiências envolvendo processos de produção. Neste esforço, pode-se ser citada, primeiramente, a pesquisa realizada por Machado, Damm e Fornari Junior (2009) sobre gabinetes de computadores usando um compósito de matriz termofixa com cerca de 3\% de resíduos de fibras de coco. Também se destaca a pesquisa realizada por Silva, Soares e Boldt (2009), que desenvolveram o compósito denominado "AKS7", constituído de matriz polimérica com reforço de fibras do papel de embalagens de cimento e o aplicaram na produção de móveis.

\section{Materiais e métodos}


O presente experimento se baseou na proposta de Teixeira (2005), que demonstrou a produção experimental de um compósito desenvolvido a partir da reciclagem de resíduos particulados de madeira, oriundos de uma madeireira. $\mathrm{O}$ material foi processado e aproveitado como insumo no processo de uma indústria de produtos em fiberglass. Ou seja, o resíduo de um processo produtivo foi considerado como insumo de um segundo. Simulou-se assim, a circulação de recursos entre duas indústrias, como o proposto pela Ecologia Industrial.

As etapas de desenvolvimento deste compósito, segundo Teixeira (2005), foram iniciadas com a coleta do resíduo e com o processamento por secagem e peneiramento. Em seguida foi feita a classificação do resíduo em três tipos, de acordo com sua granulometria: fino (F), médio (M) e grosso (G). Em seguida foram formulados 15 traços da mistura dos três tipos entre si, nas proporções de $100 \%, 50 \%$ e $33 \%$. Os traços foram depois misturados à matriz de resina poliéster insaturada (ortoftálica) em proporções de $10 \%$ e $20 \%$ de resíduo. Cada traço foi identificado com uma sigla, por exemplo: o traço GMF2 para $33 \%$ de cada tipo de resíduo misturado à $20 \%$ na matriz. Teixeira (2005), contudo, não apresentou uma aplicação do compósito desenvolvido em um protótipo de produto, o quel foi sugerido como propostas para futuras pesquisas. A realização da experiência aqui desenvolvida foi, então, ao encontro da oportunidade surgida a partir da pesquisa de Teixeira (2005).

O produto escolhido como protótipo do processo usado foi um tampo para mesa, por ser o segmento de móveis um tradicional consumidor de madeira. O procedimento foi dividido em três fases. Na Fase I foi feita a coleta de resíduos numa fábrica de produtos de madeira serrada, localizada nas cercanias da cidade de Salvador, Bahia. Essa etapa teve como objetivo conhecer o sistema produtivo e classificar seus resíduos. Na Fase II foi estudada a concepção de um protótipo, na forma de um tampo de mesa, com o objetivo de dimensioná-lo para que pudesse viabilizar o reaproveitamento da variedade dos resíduos disponíveis. Finalmente, na Fase III foi realizada a produção do tampo de mesa, usando o compósito proposto por Teixeira (2005) e pedaços descartados de madeira sólida.

\subsection{Fase I - Coleta e caracterização dos resíduos de madeira}

O procedimento ocorreu nas instalações internas e externas da madeireira. Parte foi coletada em silo de resíduos particulados e no deposito de pedaços de madeira sólida descartados. A geração destes resíduos é oriunda do beneficiamento do tronco de madeira, possuindo características bastante diferentes, sendo assim, classificados como dois tipos básicos:

- Pedaços sólidos descartados: são sobras, separadas e descartadas por defeitos ou estragos durante o processo. São tocos e pedaços de troncos sem as dimensões necessárias para serem utilizadas, tábuas rachadas, empenadas ou fora das dimensões úteis. Geralmente essas 
sobras variam de tamanho entre $15 \mathrm{~cm}$ a $1,5 \mathrm{~m}$ e os tocos com diâmetro de acordo com a tora trabalhada, mas em geral entre $10 \mathrm{~cm}$ a $20 \mathrm{~cm}$. A figura $4 \mathrm{~A}$ ilustra esse tipo.

- Particulados: gerados a partir da usinagem, corte, furação, serragem, desempeno das peças sólidas. Para cada tipo de máquina há uma serragem respectiva, pois operam diversos tipos de lâminas que, por sua vez, irão gerar diversos tipos de resíduo particulado. Muitas dessas máquinas possuem formas de coletar grande parte do resíduo, armazenando-o em um silo apropriado. Ainda assim o processo de coleta é ineficiente, pois o resíduo que sobra se espalha no chão, além de haver máquinas que o umedecem com água durante sua operação, como é o caso da serra-fita. A Figura 4B ilustra esse tipo.

Figura 4 - Tipos de resíduo coletados: em A, os pedaços sólidos descartados. Em B, os particulados

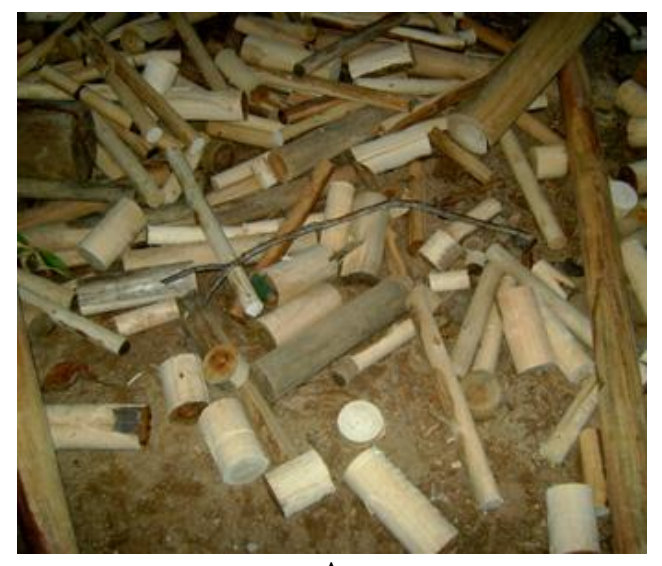

A

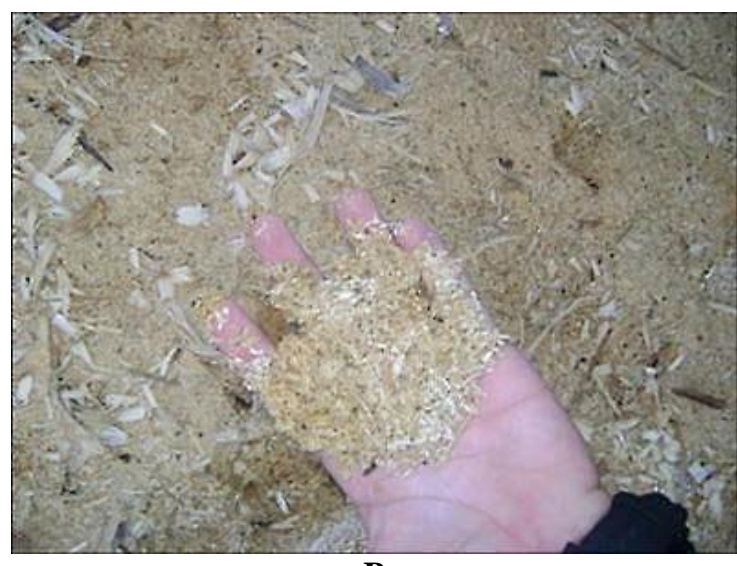

B

Fonte: fotografias dos autores

\subsection{Fase II - Concepção do produto}

A concepção do produto baseou-se nos critérios conceituais propostos nos quadros 1 e 2 . Foi feita, então, uma síntese destes critérios, mostrados no quadro 5, os quais definiram as idéias e decisões a respeito das soluções necessárias para a realização do modelo de demonstração. Com o objetivo de aumentar a abrangência sustentável do produto, os critérios foram ampliados com um item para agregar valor estético aos materiais reciclados, sugeridos por Teixeira e César (2005) e Fuad-Luke (2002).

Quadro 5 - Soluções conceituais a partir dos critérios dos quadros 1 e 2

\begin{tabular}{|cl|}
\hline Critério & \multicolumn{1}{c|}{ Solução conceitual } \\
\hline \multirow{2}{*}{ Simplificação da forma } & $\begin{array}{l}\text { - Geometrização da forma: usar um polígono regular; } \\
\text { - Pensar na modularidade, com o uso de partes e peças com } \\
\text { formato semelhante; }\end{array}$ \\
\hline Facilitar montagem & $\begin{array}{l}\text { - Minimizar quantidade de sistemas de fixação; } \\
\text { - Usar encaixes simples entre as peças; }\end{array}$ \\
\hline $\begin{array}{c}\text { Uso de materiais reciclados } \\
\text { de processos produtivos }\end{array}$ & $\begin{array}{l}\text { - Maximizar o uso da variedade de resíduos disponíveis; } \\
\text { - Usar traços de eco-compósito já testados; }\end{array}$ \\
\hline
\end{tabular}




\begin{tabular}{|cl|}
\hline $\begin{array}{c}\text { Expandir a vida útil } \\
\text { dos materiais e do produto }\end{array}$ & $\begin{array}{c}\text { - Aumentar a proteção aos materiais usados contra as intempéries } \\
\text { e demais ameaças que possam degradá-los; }\end{array}$ \\
\hline $\begin{array}{c}\text { Tecnologias limpas e } \\
\text { processos acessíveis }\end{array}$ & - Usar técnicas simples e equipamentos manuais de marcenaria, \\
\hline $\begin{array}{c}\text { Agregar valor estético aos } \\
\text { materiais reciclados }\end{array}$ & - Procurar minimizar o uso de energia elétrica e de água; \\
\hline & - Minimizar as cores e texturas naturais dos materiais, \\
\hline
\end{tabular}

Fonte: Manzini e Vezzoli (2002), Fuad-Luke (2002), Teixeira (2005) e Teixeira e César (2005)

Com o objetivo de conceber uma solução que aproveitasse ambos os resíduos na construção do protótipo de forma mais eficiente foi proposta a geometrização da sua forma, para permitir que as partes sólidas de pequenas dimensões pudessem constituir os lados de um polígono regular. $\mathrm{O}$ octógono foi o formato geométrico escolhido, como proposta de maximização do aproveitamento de peças descartadas, sem aumentar, contudo, a dificuldade de produção das peças do produto. Primeiramente foi idealizada uma estrutura octogonal, aqui denominada de Anel Estrutural, proposto em oito peças separadas, mas idênticas, que servirão como estrutura mecânica do tampo. As dimensões propostas foram as similares aos de uma mesa plástica comum, com diâmetro de 90 $\mathrm{cm}$ e espessura de $5 \mathrm{~cm}$. Esta solução foi baseada na possibilidade de uso de técnicas básicas de marcenaria, através de processos de corte reto e uso de encaixes tipo espigão. Em seguida, foi idealizada a tampa interna, construída com o compósito sugerido por Teixeira (2005), e projetada para ser encaixada e fixada no Anel Estrutural. A representação gráfica da solução está mostrado na figura 5 .

Figura 5 - Desenho da concepção do protótipo do tampo de mesa

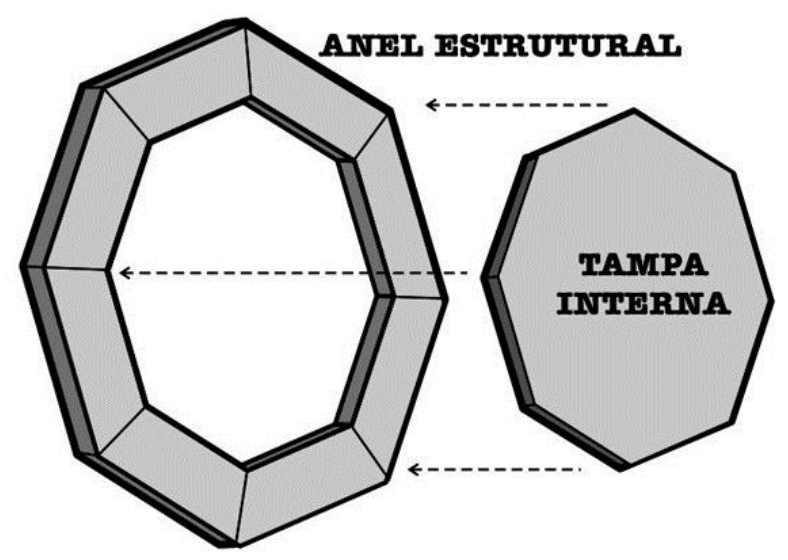

Fonte: construção própria

Com o objetivo de agregar valor estético e ao mesmo tempo aumentar a proteção aos materiais reciclados usados no protótipo, foi idealizado o uso de vernizes no anel estrutural, solução que evidencia o desenho e textura natural da madeira sólida, aumentando a durabilidade do produto. Para a tampa interna, Teixeira (2005) apontou para as boas características plástica e estética, aliadas à resistência física e a baixa absorção de água apresentada pelo compósito. Essas características permitem seu uso direto no produto sem a necessidade da aplicação de tintas ou de revestimentos. 


\subsection{Fase III- Produção do protótipo}

Esta fase foi realizada em quatro etapas. Na primeira, foi construído o anel estrutural, com formato octogonal, construído a partir de pedaços de tábuas de pinus descartadas. A segunda etapa compreendeu produção do compósito com o resíduo particulado e posterior confecção da Tampa Interna. Na terceira etapa foi moldada a tampa interna e na ultima etapa foi realizada a montagem final do produto.

Etapa 1: Montagem do Anel Estrutural. Os pedaços descartados foram selecionados e cortados de acordo com um gabarito. Depois encaixados e colados com cola de madeira, usando união tipo espigão. A figura 6 mostra a sequência de produção.

Figura 6 - Fase III - Etapa 1

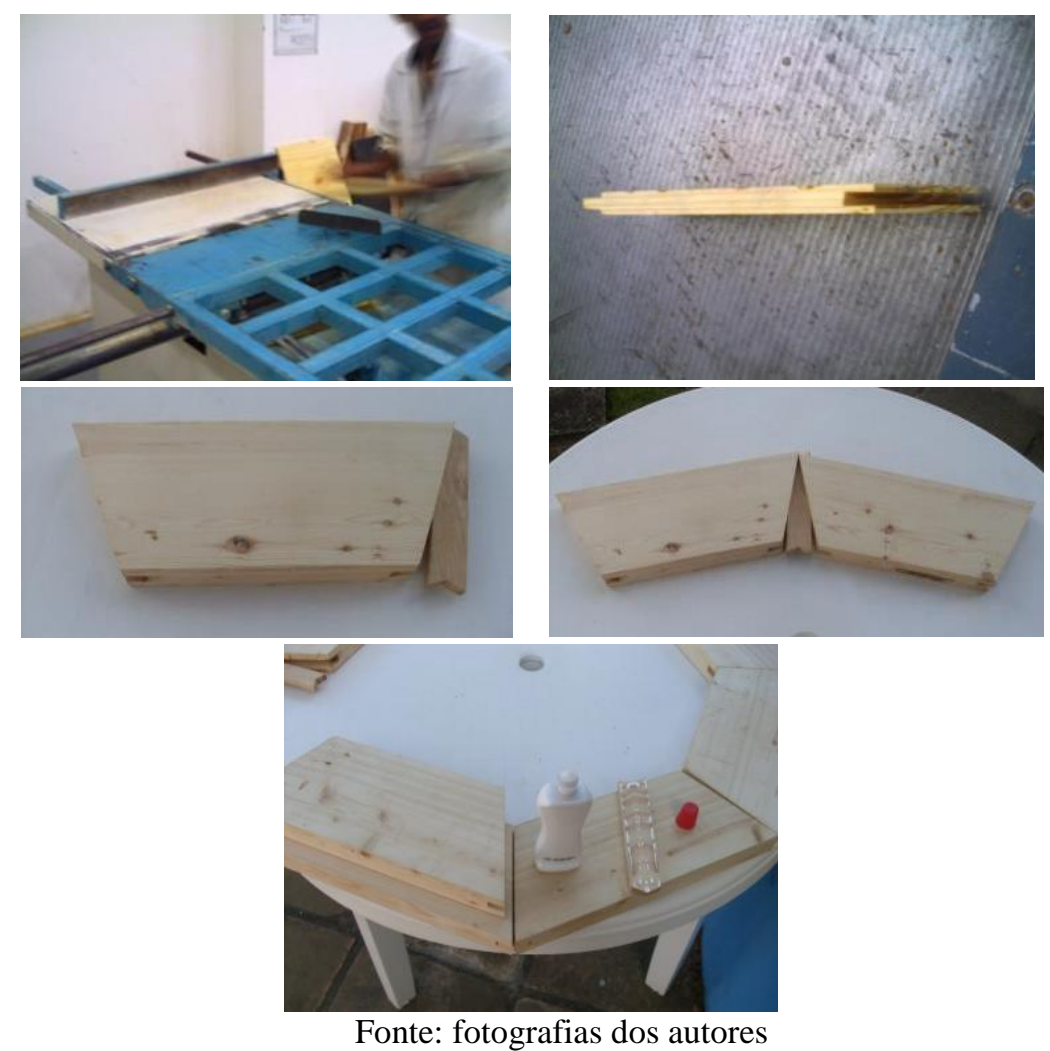

Etapa 2: Produção do compósito. Desenvolvido segundo o método sugerido por Teixeira (2005). Foi adotado, entretanto, uma variação do traço GMF2, cuja mistura original era de $33 \%$ para cada tipo granulométrico (fino, médio e grosso), para um compósito contendo 40\% de resíduo fino, $40 \%$ do médio e $20 \%$ do grosso. Essa variação foi escolhida visando o melhor preenchimento de espaços na matriz polimérica. O resíduo foi então secado, peneirado e misturado, seguindo o novo traço, à matriz termofixa de poliéster no teor de $20 \%$ e catalisado a $1 \%$ (Figura 7 ).

Figura 7 - Fase III - Etapa 2: Componentes do compósito 


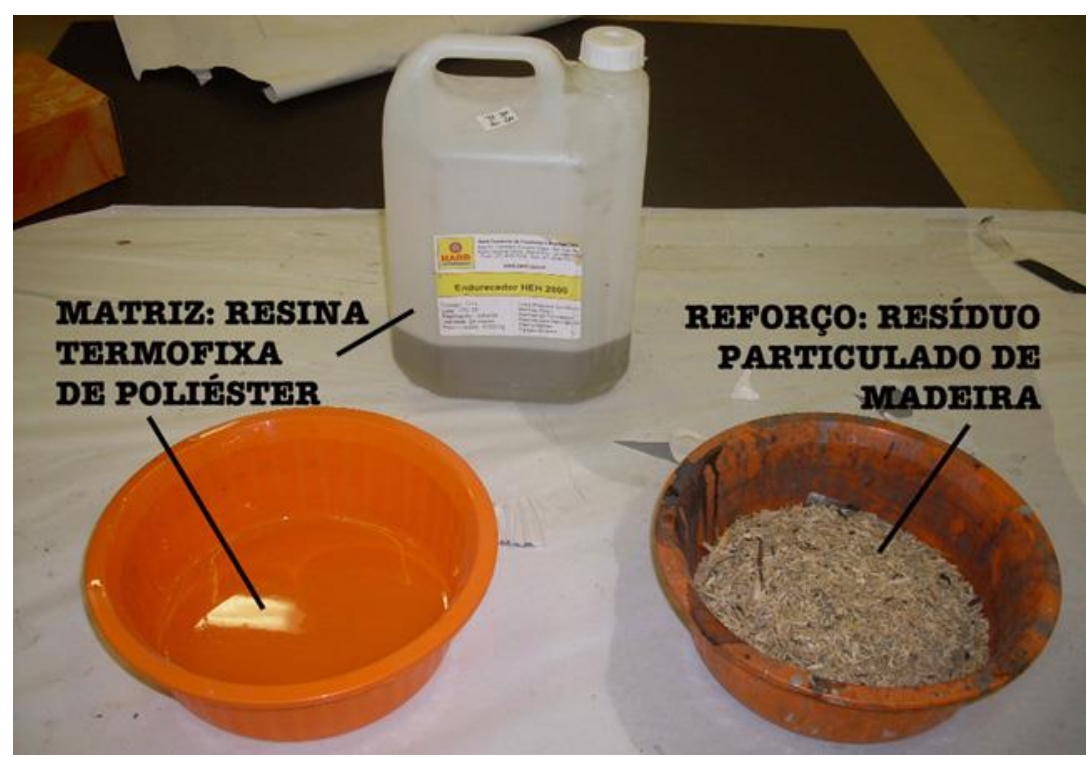

Fonte: fotografia dos autores

Etapa 3: Moldagem da Tampa Interna: Devido ao tamanho da Tampa Interna, optou-se por uma moldagem em molde aberto, diferentemente a aquela proposta por Teixeira (2005), que usou moldes fechados para a produção de pequenos corpos de prova. Neste caso, o molde foi construído com pedaços de vidro plano, no qual foram erguidas paredes de tiras de papelão couro na altura de $5 \mathrm{~cm}$ no formato octogonal. A figura 8 mostra uma das peças de vidro usadas como molde e a Tampa Interna em processo de cura.

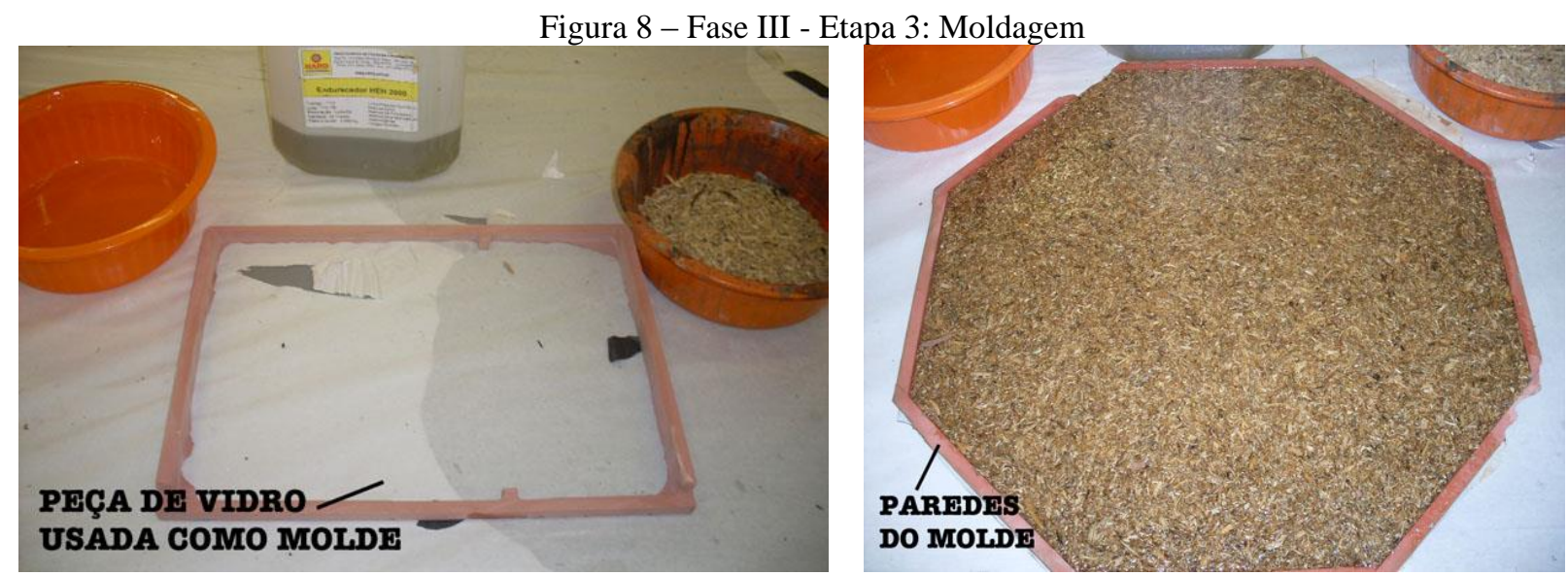

Fonte: fotografias dos autores

Etapa 4 - Montagem final: A escolha por produzir as peças separadamente resultou numa etapa de montagem como mostrado anteriormente na Figura 5. Primeiramente a tampa Interna teve suas arestas lixadas para permitir o encaixe com o Anel Estrutural, visto que estava ligeiramente maior que a abertura. A colagem das peças foi realizada usando a própria resina de poliéster, criando uma fixação definitiva entre ambas. Alguns espaços entre as peças foram preenchidos com o compósitio. A figura 9 mostra a montagem final do produto sem acabamento e uma foto, em escala real, da interface entre as peças, colada com a resina. 
Figura 9 - Fase III - Etapa 4: montagem das peças
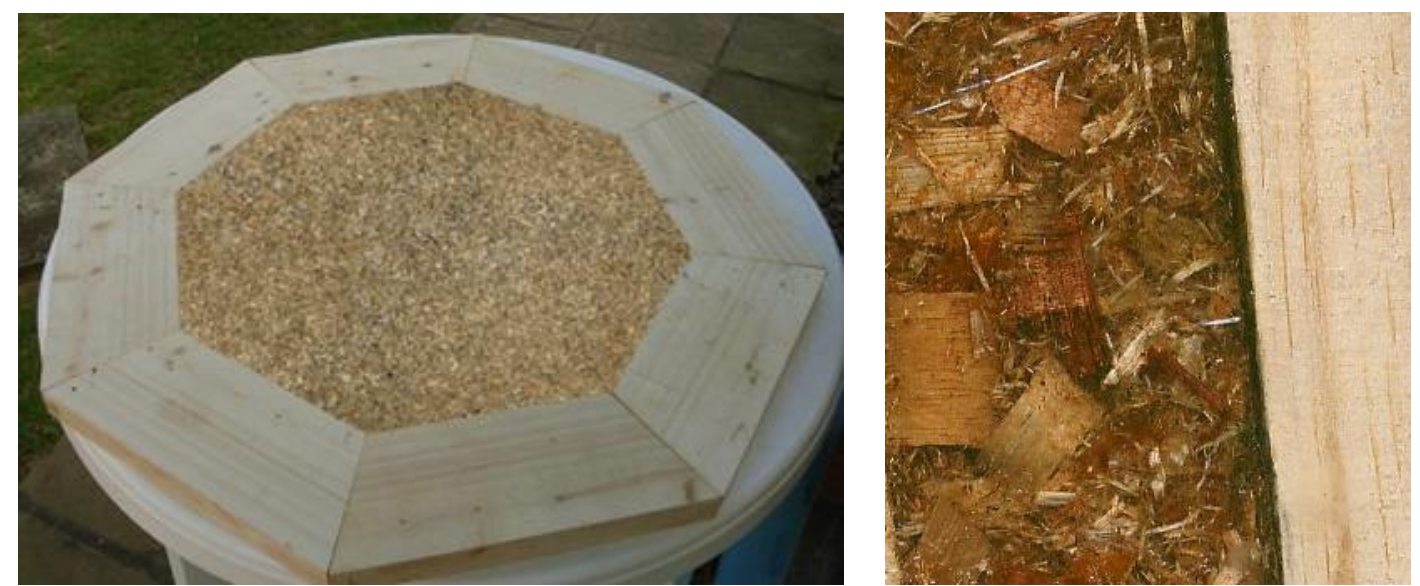

Fonte: fotografias dos autores

Após a cura do compósito, o anel estrutural recebeu uma aplicação de verniz do tipo tingidor, com cor escura, como solução de proteçâo e para por em evidência a textura da madeira. Assim criou-se um contraste de cor entre as peças, valorizando-as esteticamente. O produto finalizado é mostrado na Figura 10.

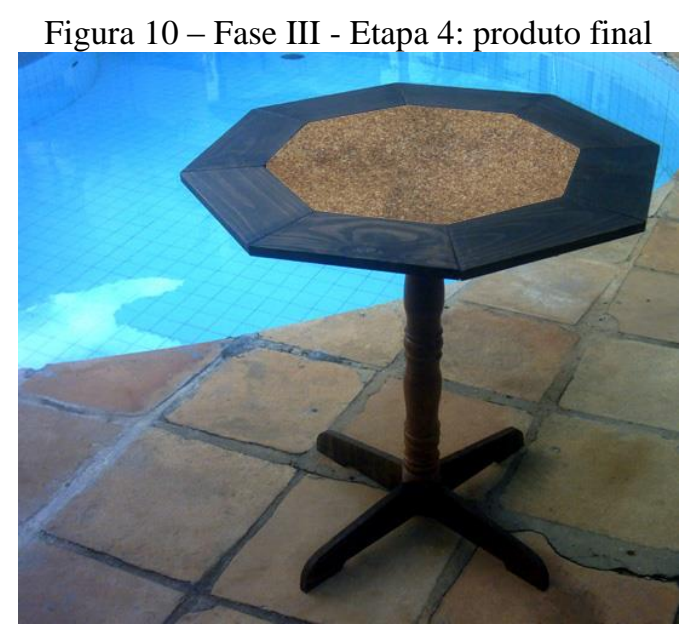

Fonte: fotografias dos autores

\section{Considerações Finais}

Quanto aos propósitos da Ecologia Industrial, o objetivo alcançado demonstrou a sua viabilidade, tanto na confirmação da produção de um eco-compósito, defendido em pesquisas anteriores (TEIXEIRA, 2005), como também no design e produção de um produto final usando este material. Além disso, esta pesquisa buscou ir além, ao conjugar pedaços sólidos descartados e resíduos particulados aos processos de concepção e desenvolvimento de novos produtos sustentáveis, mostrando resultados plásticos aceitáveis. Demonstrou-se também que é possível a fabricação de produtos híbridos entre as duas tecnologias: a da madeira e a dos plásticos reforçados.

A escolha do molde aberto trouxe vantagens e desvantagens: Como vantagem, o fato de o molde de vidro possuir a característica de passar para a peça fabricada uma superfície polida e com muito brilho, aumentando a beleza plástica do produto. Como desvantagem, a confirmação de que o 
molde aberto não evita a emissão de vapores orgânicos da matriz durante a cura do compósito. Por outro lado, a escolha pela colagem das peças se justificou por ter sido considerada como uma alternativa simples e de baixo custo, apesar de dificultar a desmontagem do produto.

Como proposta para novas pesquisas, sugere-se estudar primeiramente formas de reúso ou remanufatura do produto, ou mesmo a reciclagem da madeira e do compósito no qual foi fabricado, buscando satisfazer o princípio da circulação de recursos propostos pela Ecologia Industrial. Sugere-se ainda o estudo do uso de moldes fechados como processo produtivo e também de sistemas de fixação não permenentes, para uso na interface entre as peças de madeira e de compósito, como alternativa à colagem das peças, com o objetivo de facilitar a desmontagem do produto.

\begin{abstract}
This article aims to demonstrate the application of concepts of Industrial Ecology and Eco-design as a basis for the design of products built with particulate waste and solid pieces of discarded wood, considered as waste without an apparent solution. Current research took as its starting point previous studies on production of an ecological composite made from waste sawdust, which was expanded to take parts of discarded solid wood. Based on the use of materials in closed flow concept, proposed by the Industrial Ecology and Eco design requirements, it was designed as a demonstration model, a table top. Was used for this, a method of three phases: Phase I, gathering and classification of wood waste in a timber industry; Phase II, the design of the product and in Phase III, the production of the demonstration model. The solution was to use the various waste in different parts of the model, thereby generating an artistically pleasing result.
\end{abstract}

Key-words: Industrial Ecology; Eco-Design, wood waste

\title{
Referências
}

ABNT. NBR 10004 - Resíduos Sólidos. Rio de Janeiro: Associação Brasileira de Normas Técnicas. 1987.

ALLENBY, B. R. Y. RICHARDS, D. J., Orgs.. The greeninig of industrial ecosystems. Washington, D.C.: National Academy Press. 1994. 268p.Disponível em http://books.nap.edu/openbook.php?record_id=2129\&page=R1. Acessado em agosto de 2014.

ALVES, A. P. F.. TREVISAN, M.. Ecologia Industrial na Prática: oportunidades e limitações para a instalação de uma indústria de brita ecológica em Rio Grande/RS. Revista eletrônica de gestão, educação e tecnologia. V. 18 n. 1 Abr. 2014, p. 144-157. Disponível em http://cascavel.ufsm.br/revistas/ojs-2.2.2/index.php/reget/article/view/11007

Acessado em julho de 2014.

ALVES, W. F. et al. Caracterização do compósito de poliuretano derivado do óleo de mamona (pur) com sílica obtida da planta "cavalinha". In $9^{\circ}$ CONGRESSO BRASILEIRO DE POLÍMEROS. Campina Grande. 2007. Anais....

Disponível em: http://ainfo.cnptia.embrapa.br/digital/bitstream/item/89448/1/proci-07.00034.PDF Acessado em julho de 2014.

ARAÚJO, H. J. B. de. Aproveitamento de resíduos das indústrias de serraria do Acre para fins energéticos.

Comunicado Técnico 82. Rio Branco: Embrapa. 2003. Disponível em http://iquiri.cpafac.embrapa.br/pdf/doc82.pdf Acessado em julho de 2014.

BARANOWSKI, C.; SHREVE, D. Open mold processing In AGRANOFF, J. (Editor) Modern Plastics Encyclopedia 1981-82: engineering data, design guide, textbook, directory. New York: McGraw-Hill. 1981. 938p. 
BRASKEM. Glossário de Termos Aplicados a Polímeros. Boletim Técnico No 08 P. 2 Camaçari, 2002. Disponível em http://www.braskem.com.br/Portal/Principal/Arquivos/html/boletm_tecnico/Glossario_de_termos_aplicados_a_polimer os.pdf . Acessado em setembro de 2015.

CLAVADETSCHER, D. Closed mold processing. In AGRANOFF, J. (Editor) Modern Plastics Encyclopedia 198182: engineering data, design guide, textbook, directory. New York: McGraw-Hill. 1981. 938p.

CORREA, Carlos A. et al . Compósitos termoplásticos com madeira. Polímeros, São Carlos, v. 13, n. 3, p. $154-165$. 2003. Disponível em http://www.scielo.br/pdf/po/v13n3/v13n3a05.pdf Acessado em agosto de 2015.

DA SILVA, C.A. P.. Linha Redonda - um exemplo de uso racional da madeira. In $1^{\circ}$ CONGRESSO INTERNACIONAL DE PESQUISA EM DESIGN E $5^{\circ}$ CONGRESS BRASILEIRO DE PESQUISA E DESENVOLVIMENTO EM DESIGN. Brasília, UNB, 2002. Anais... CD ROM

DOS SANTOS, E. A.. Avaliação mecânica e microestrutural de compósitos de matriz de poliéster com adição de cargas minerais e resíduos industriais. Natal. Universidade Federal do Rio Grande do Norte. 2007. Dissertação. Disponível em: http://repositorio.ufrn.br:8080/jspui/handle/1/11079 Acessado em julho de 2014.

EHRENFELD, J.. GERTLER, N.. Industrial Ecology in Practice. The Evolution of Interdependence at Kalundborg. Journal of Industrial Ecology. V1, N1. 67-80. 1997. Disponível em http://www.johnehrenfeld.com/Kalundborg.pdf Acessado em julho de 2014.

EL-HAGGAR, S. M. KAMEL, M. A. Wood Plastic Composites. In TESINOVA, P.: Advances in Composite Materials - Analysis of Natural and Man-Made Materials. Egypt: InTech. 2011. Disponível em:

www.intechopen.com/books/advances-in-composite-materials-analysis-ofnatural-and-man-made-materials/woodplastic-composites Acessado em julho de 2014.

ENGLISH, Brent. Wastes into Wood: Composites Are a Promising New Resource. Environmental Health Perspectives. Vol. 102, No. 2. 1998. Disponível no site:

http://www2.bren.ucsb.edu/ modular/private/Articles/Waste\%20into\%20wood.pdf . Acessado em agosto de 2015. FIKSEL, J.. Design for Environment: A Guide to Sustainable Product Development. New York; McGraw-Hill. 2009 .

FREITAS, L. C. de. A baixa produtividade e o desperdício no processo de beneficiamento da madeira: um estudo de caso. Florianópolis: Universidade Federal de Santa Catarina - UFSC.. 2000. Dissertação. Disponível em: https://repositorio.ufsc.br/handle/123456789/78577 Acessado em agosto de 2014.

FUAD-LUKE, Alastair. Manual de diseño ecológico. Um catálogo completo de mobiliario y objetos para la casa y la oficina. Palma de Mallorca: Editorial Cartago, 2002.

GARAY, André C. et al. Influence of calcium carbonate on RTM and RTM light processing and properties of molded composites. Journal of Reinforced Plastics and Composites n 30 v 14. 2011. Disponível em http://www.ufrgs.br/lapol/influence_of_calcium.pdf Acessado em agosto de 2015.

GAY. D. HOA, S. V. TSAI, S. W. Composite Materials: design and applications. Londres: CRC Press. 2003.

GOMES, J. I. SAMPAIO, S. S.. Aproveitamento de resíduos de madeira em três empresas madeireiras do Estado do Pará. In Comunicado Técnico 102. Belém do Pará: Embrapa 2004. Disponível em:

http://www.bibliotecaflorestal.ufv.br/bitstream/handle/123456789/7139/Comunicado_Tecnico_102.pdf?sequence=1 Acessado em julho de 2014.

GONÇALVES, M. T. T. RUFFINO, R. T.. Aproveitamento do Resíduo Gerado na Indústria Madeireira. In III EBRAMEM - ENCONTRO BRASILEIRO EM MADEIRAS E EM ESTRUTURAS DE MADEIRA. São Carlos. 1989. Anais... São Carlos, SP. USP - EESC. 1989. p 129 à 140. CD ROM

ISENMANN, R. Industrial ecology: shedding more light on its perspective of understanding nature as a model. Sustainable Development. v. 11, n. 3, p. 143-158, 2003. Disponível em:http://www.homepages.ucl.ac.uk/ ucessjb/S3\%20Reading/isenmann\%202003.pdf Acessado em julho de 2014.

JACOBSEN, N. B.. Industrial Symbiosis in Kalundborg, Denmark. A Quantitative Assessment of Economic and Environmental Aspects. Journal of Industrial Ecology. V.10, N.1-2. 2006. Disponível em: http://www.exima.dk/cases/Journal_of_Industrial_Ecology_1012239.pdf Acessado em julho de 2014. 
KIPERSTOK, A.; MARINHO M. Ecologia Industrial e Prevenção da Poluição: Uma Contribuição Ao Debate Regional. Bahia Análise \& Dados, SEI, V.10, nº, p271-279, Março, 2001. Disponível no site: http://www.teclim.ufba.br/site/material_online/publicacoes/pub_art10.pdf Acessado em agosto de 2014.

MACHADO, K. C.. DAMM D. D.. FORNARI JUNIOR C. C. M. Reaproveitamento tecnológico de resíduo orgânico: casca de coco verde na produção de gabinetes ecológicos de computadores. In $2^{\circ}$ Forum Internacional de Resíduos Sólidos. Ilhéus. 2009. Anais... Disponível em: http://www.institutoventuri.com.br/t013.pdf Acessado em julho de 2014.

MANISH RESINS \& POLYMERS PRIVATE LIMITED. FRP Process. 2014. Disponível em: http://www.frprawmaterial.com/frp-process.html. Acessado em novembro de 2014.

MANZINI, E.. VEZZOLI, C.. O desenvolvimento de produtos sustentáveis. Os requisitos ambientais dos produtos industriais - São Paulo: Edusp - 2002.

MARTUSCELLI, C. C. Efeito da adição de resíduos de borracha de pneus nas propriedades de compósitos polímeros-cerâmicos. São João del Rei: Universidade Federal de São João del Rei. 2013. Dissertação. Disponível em: www.ufsj.edu.br/portal2-repositorio/File/ppmec/Carolina\%20Coelho\%20Martusceli.pdf Acessado em julho de 2014. MAZZETTO, S. E.; LOMONACO, D.; MELE, G.. Óleo da castanha de caju: oportunidades e desafios no contexto do desenvolvimento e sustentabilidade industrial. Química Nova, V. 32, N. 3, 2009. Disponível em: http://www.scielo.br/scielo.php?pid=S0100-40422009000300017\&script=sci_arttext Acessado em julho de 2014.

MISSAGIA, Z. M. V. et al. Materiais compósitos particulados em matriz epóxi reforçados com serragem, cimento e silicato de magnésio. Ambiente Construído. V. 13, N. 3, p. 285-302, jul./set. 2013. Disponível em http://www.scielo.br/scielo.php?pid=S1678-86212013000300017\&script=sci_arttext Acessado em julho de 2014.

MISSAGIA, Z. M. V.. Compósitos particulados em matriz epóxi reforçados com serragem, cimento e silicato de magnésio. São João Del-rei : Universidade Federal de São João Del-rei, 2013. Dissertação. Disponível em: http://www.ufsj.edu.br/portal2-repositorio/File/ppmec/dissertacao_zelia.pdf Acessado em julho de 2014.

MOLINARI, É. J.. Reutilização dos resíduos de rochas naturais para o desenvolvimento de compósitos poliméricos com matriz termofixa na manufatura de pedras industriais. Santa Catarina : Universidade Federal de Santa Catarina, 2007. Dissertação. Disponível em:

https://repositorio.ufsc.br/bitstream/handle/123456789/89624/245531.pdf?sequence=1 Acessado em julho de 2014.

OGUNTOKEA, O. OTUSANYAB, O. K. ANNEGARN, H.J. Emission of pollutants from wood waste incineration at sawmills in Abeokuta metropolis. International Journal of Environmental Studies. V.70, I. 6, 2013. Disponível em http://www.tandfonline.com/doi/full/10.1080/00207233.2013.845709\#tabModule Acessado em julho de 2014.

ORTH, Cíntia Madureira. BALDIN, Nelma. ZANOTELLI, Cladir Teresinha. Implicações do processo de fabricação do compósito plástico reforçado com fibra de vidro sobre o meio ambiente e a saúde do trabalhador: o caso da indústria automobilística. Revista Produção Online, v.12, n. 2. 2012. Disponível em: http://producaoonline.org.br/rpo/article/view/943. Acessado em agosto de 2015.

PINHEIRO, G. F. RENDEIRO, G. PINHO, J. T. Resíduos do setor madeireiro: aproveitamento energético. Biomassa \& Energia, V. 1, N. 2, p. 199-208, 2004. Disponível em http://www.renabio.org.br/09-B\&E-v1-n2-2004-199-208.pdf. Acessado em julho de 2014.

QUIRINO, W. F. Utilização Energética de Resíduos Vegetais. Brasília: Laboratório de Produtos Florestais LPF/IBAMA..S/D Disponível no site: www.funtecg.org.br/arquivos/aproveitamento.pdf. Acessado em maio de 2004. RAMASWAMY, R.. Industrial Ecology: A New Platform for Planning Sustainable Societies. In Proceedings of the 2003 Berlin conference on the human dimensions of global environmental change. Berlim. 2004. Anais. Disponível em http://userpage.fu-berlin.de/ffu/akumwelt/bc2003/proceedings/448\%20-\%20458\%20ramaswamy.pdf Acessado em julho de 2014

RODRIGUES, S. C.. PEIXOTO, J. A. A.. XAVIER, L. de S.. Formação de cadeia verde de suprimento a partir da gestão sustentável de resíduos industriais - um exemplo no setor de reciclagem. Sistemas \& Gestão. N.8, p 44-57 2013. Disponível em http://www.uff.br/sg/index.php/sg/article/view/V8N1A4 Acessado em julho de 2014.

SCHIRMER. Waldir Nagel et al. Desempenho ambiental em indústrias de base florestal - estudo de caso na região centro-sul do Paraná. Revista Gestão Industrial. v. 06, n. 03: p. 100-114, 2010. Disponível em: https://periodicos.utfpr.edu.br/revistagi/article/view/580 Acessado em agosto de 2015. 
SILVA, C. B. da. O Design como Estratégia de Diferenciação para Micro e Pequenas Empresas: o caso da indústria moveleira em dois municípios do estado do amazonas. Florianópolis: UFSC. 2004 - Dissertação.. Disponível em: https://repositorio.ufsc.br/bitstream/handle/123456789/86890/214054.pdf?sequence=1. Acessado em agosto de 2014.

SILVA, C. T. da. Avaliação de metodologia de obtenção do ácido tereftálico via reciclagem química do PET. Rio de Janeiro: UFRJ. 2012. Dissertação. Disponível em: http://tpqb.eq.ufrj.br/download/acido-tereftalico-via-reciclagemquimica-do-pet.pdf Acessado em julho de 2014.

SILVA, E. P.da. SOARES, M. P.. BOLDT, R. S.. Aplicação do compósito AKS7 no design de móveis. In $2^{\circ}$ Simpósio Brasileiro De Design Sustentável (II SBDS). São Paulo. 2009. Anais... Disponível em: http://portal.anhembi.br/sbds/anais/SBDS2009-008.pdf Acessado em julho de 2014.

SILVA, F. C. da. Fabricação de eco-composito com a fibra de lã canina. Natal: Universidade Federal do Rio Grande do Norte. Natal. 2012. Dissertação. Disponível em: http://repositorio.ufrn.br:8080/jspui/handle/1/11099 Acessado em julho de 2014.

SILVA, J. L. P. da. Aproveitamento de resíduos da indústria madeireira para geração de energia elétrica - o caso da empresa B. K. Energia Itacoatiara Itda no Estado do Amazonas. Curitiba: UFPR. 2011. Monografia Lato Sensu.. Disponível em:

http://dspace.c3sl.ufpr.br/dspace/bitstream/handle/1884/32733/JOSE\%20LAZARO\%20PINHEIRO\%20DA\%20SILVA .pdf? sequence=1 Acessado em julho de 2014.

SOUZA, W. B. Estudo da adição de lama de bauxita em polímero de poli (metacrilato de metila) por meio de polimerização em massa e moldagem em casting. São Paulo: Instituto de pesquisas energéticas e nucleares / USP. Dissertação. Disponível em http://pelicano.ipen.br/posg30/textocompleto/wander\%20burielo\%20de\%20souza_m.pdf Acessado em julho de 2014.

TAKAHASHI, Rafael et al. Fabricação de mantas de fibras de sisal e de curauá para fabricação de material compósito. XXXIX COBENGE: Congresso brasileiro de educação em engenharia. 2011. Anais. Disponível em: http://www.abenge.org.br/CobengeAnteriores/2011/sessoestec/art1765.pdf Acessado em setembro de 2015.

TANIMOTO, A. H.. Proposta de simbiose industrial para minimizar os resíduos sólidos no Pólo Petroquímico de Camaçari. Salvador: Universidade Federal da Bahia. 2004 Dissertação. Disponível em:

http://www.teclim.ufba.br/site/material_online/dissertacoes/dis_armando_h_tanimoto.pdf Acessado em agosto de 2014.

TEIXEIRA, M. G.. Aplicação de conceitos da ecologia industrial para a produção de materiais ecológicos: o exemplo do resíduo de madeira. Salvador: Universidade Federal da Bahia.. 2005. Dissertação. Disponível em: http://www.teclim.ufba.br/site/material_online/dissertacoes/dis_marcelo_g_teixeira.pdf Acessado em julho de 2014.

TEIXEIRA, Marcelo Geraldo. CÉSAR, Sandro Fábio. Ecologia Iindustrial e Eco-design: requisitos para a determinação de materiais ecologicamente corretos Revista Design em Foco, ano/vol. II, número 001. Disponível em: http://www.redalyc.org/articulo.oa?id=66120105 Acessado em agosto de 2015.

TEIXEIRA, M.G. SANTOS, E. R. B. Aplicação de conceitos da ecologia industrial na produção de roupas a partir de uniformes descartados. Revista Sodebras. Volume 10 - n. 117. Pag. 267 à 271. Disponível em:

http://www.sodebras.com.br/edicoes/N117.pdf Acessado em agosto de 2015.

VAZZOLER. Dirceu. Fabricação de peças automotivas nos processos de SMC / BMC / RTM / RTM Light. Reichhold. Painel Automotivo. São Paulo. 2010. Disponível em:

http://www.tecnologiademateriais.com.br/mt/2010/cobertura_paineis/automotivo/apresentacoes/reichhold.pdf Acessado em agosto de 2015 .

WIECHETECK, M.. Aproveitamento de resíduos e subprodutos florestais, alternativas tecnológicas e propostas de políticas ao uso de resíduos florestais para fins energéticos. Curitiba: Ministério do Meio Ambiente. 2009. Disponível em http://www.mma.gov.br/estruturas/164/_publicacao/164_publicacao10012011033501.pdf Acessado em julho de 2014.

ZONATTI, W. F. Estudo interdisciplinar entre reciclagem têxtil e o design: avaliação de compósitos produzidos com fibras de algodão. São Paulo: Universidade de São Paulo. 2013. Dissertação. Disponível em:

http://www.teses.usp.br/teses/disponiveis/100/100133/tde-13032013-015305/pt-br.php Acessado em julho de 2014. 


\section{Dados dos autores:}

Nome completo: Marcelo Geraldo Teixeira

Filiação institucional: Faculdade Ruy Barbosa | DeVry Brasil

Departamento: Design

Função ou cargo ocupado: Professor

Endereço completo para correspondência: Rua Rogério de Faria, 166. Apto 501. Rio Vermelho.

Salvador - Ba. CEP 41.940-300

Telefones para contato: Cel. 71-9943-1968 Tel. 71-3351-6508

e-mail:marcelomgt@gmail.com

Nome completo: Elio Carlos dos Santos Junior

Filiação institucional: Faculdade da Cidade

Departamento: Design

Função ou cargo ocupado: Graduado

Endereço completo para correspondência: Rua tiradentes ,1837 bloco 03, apartamento 01. Bairro:

Santa Terezinha. Sao bernado do campo cep 09781-220 Sao paulo

Telefones para contato: 01129171276 fixo e o celular 011981239786

e-mail: elio-paulista@hotmail.com

Nome completo: Evanes Copque dos Santos Couto

Filiação institucional: Faculdade da Cidade

Departamento: Design

Função ou cargo ocupado: Graduado

Endereço completo para correspondência: R do Uruguai, 753, Uruguai, Salvador, BA

Telefones para contato: (71) 8839-2972 / (71) 3313-4704

e-mail: kopke_@hotmail.com

Submissão: $18 / 09 / 2015$

Aceito: 06/03/2016 